\title{
Promoting Academic Exchange in Public Health: A Transnational Education Model
}

\author{
Ma. Lourdes Domingo-Maglinao, MD, \\ Leilani B. Mercado-Asis, MD, PhD, MPH, MEd (DE)
}

\begin{abstract}
International collaborative Master in Public Health programs provide students wider opportunities to engage in vital public health related work with specific populations and communities to improve health through awareness, education, policy, and research. A transnational education model to promote academic exchange in public health is hereby showcased with the collaboration of the University of Santo Tomas, Faculty of Medicine and Surgery and the University of Leeds, Nuffield Center for International Health and Development. The program was established through initial institutional visits of each respective staff, faculty capacity building through workshops and symposia, and final agreement on a laddered structure of curriculum. This article describes how this program was established.
\end{abstract}

\section{INTRODUCTION}

Public health in simple terms means protecting the health of the population through preventing disease, prolonging life, and promoting health through the organized efforts of different sectors of the community and society.[1] Unlike clinical professionals who diagnose and treat diseases, public health professionals try to prevent problems from happening or recurring through implementing

Leilani B. Mercado-Asis, MD, PhD, MPH, MEd (DE) Imasis@ust.edu.ph

Department of Medicine,

Faculty of Medicine and Surgery,

University of Santo Tomas, Espana,

Manila, Philippines educational programs, formulating policies, administering services, and conducting research. Public health also works to limit health inequalities. A large part of public health is promoting healthcare accessibility, equity, and quality.[2]

A Master in Public Health (MPH) degree is a graduate-level degree that prepares individuals to work with specific populations and communities to improve their health through awareness, education, policy, and research. An MPH program will provide students with a more advanced understanding of the five core disciplines of public health (biostatistics, epidemiology, environmental health, health policy and administration, and social and behavioral sciences) and the potential for advanced knowledge in a given specialization.[3]

International collaborative MPH programs prepare students to work in situations with an international setting. Programs may come in various levels, from direct attendance of courses in a foreign institution and direct practice in foreign countries, to administrative positions in government, nonprofit, and private-sector organizations. A strong MPH in Global Health must take into account all of the cultural, ethical, legal, and economic factors involved in public health, and teach students to translate programs into a variety of cultural and political settings. One advantage to be in an international program is to provide students wider horizons for connections with national and international public health organizations and help launch their careers. [4]

In this article, the establishment of the collaborative laddered program between the University of Santo Tomas, Faculty of Medicine and Surgery (UST-FMS) and University of Leeds (UoL), Nuffield Center for 


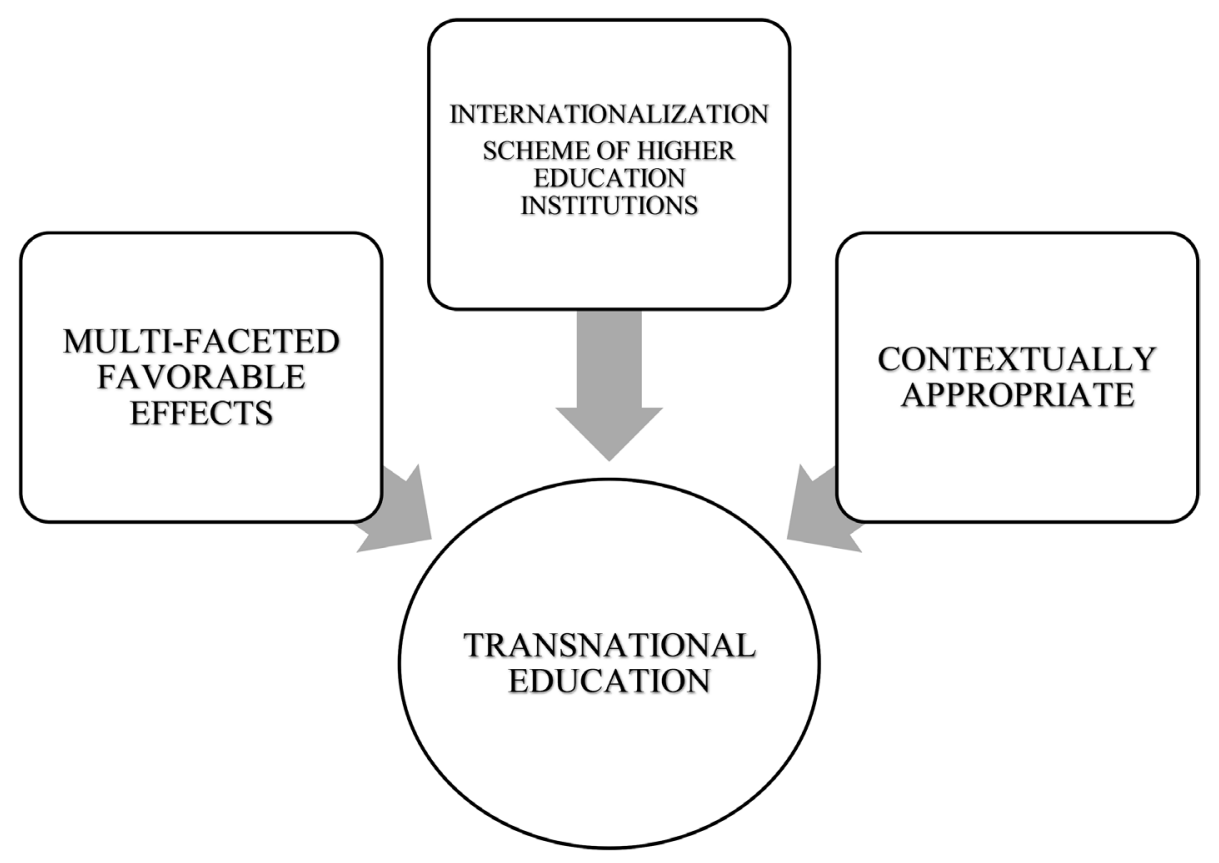

Figure 1. Elements in the transnational education (TNE).

International Health and Development (NCIHD) will be discussed. This is the first collaborative partnership in international public health education ever established in the Philippines by two distinguished and renowned institutions globally.

\section{Transnational Education (TNE) and Global Partnership}

TNE through global partnerships becomes an inherent element of the internationalization scheme of higher education institutions. TNE can result in multifaceted favorable effects on institutions of higher learning (eg, instructional, employment, economic, socio-cultural) (Figure 1). Growth in TNE, which is expected to continue its upward trajectory, has inspired the emergence of numerous approaches, including but not limited to international branch campuses (IBCs), twinning programs, articulation programs, joint degrees, and online courses. It is becoming increasingly apparent, however, that in order for a program to succeed it must be contextually appropriate and as a result, numerous factors must be taken into consideration when developing such TNE partnerships.

Through the British Council and the Commission on Higher Education (CHED), top Philippine universities partner with the United Kingdom (UK) to offer collaborative programs. Through the two-year British Council and CHED collaborative project,
Joint Development of Niche Programmes through Philippine-UK Linkages, the Philippine universities have geared up to partner with UK universities to offer UK degrees.

\section{Master of Public Health International: A Team- up of Two Excellent Institutions}

The Faculty of Medicine and Surgery, University of Santo Tomas (UST) and the Nuffield Center for International Health and Development, UoL engaged in a pioneering, reciprocal academic exchange which is the Master in Public Health International by the UST with Post Graduate Certificate of Public Health International by the UoL.

The UST-FMS is the oldest medical school in the Philippines. The UST-FMS produces over 400 medical graduates with over $95 \%$ passing rate in the National Board Examination. The faculty has been marked as the Center of Excellence in Medicine by the Philippine CHED and gained the top medical school status in 2017. The UST is a comprehensive higher education institution (HEI), offering 188 degree courses, 78 of which are postgraduate. Its internationalization strategy aims to expand opportunities for students and faculty on cross-cultural immersions through mobility programs, visiting international academics, hosting International conferences, joint thematic conferences, national and international research collaboration, and joint/dual degree programs, 
and TNE. The UST is rated high in the QS global ranking among Asian universities counterpart.[5] It has recently established its own journal, the Journal of Medicine UST (JMUST) and its published research outputs are highly cited. The UST also has high employability of its graduates.

The UoL has been granted gold for teaching excellence by the Teaching Excellence Framework (TEF) for delivering consistently outstanding teaching, learning, and outcomes for its students.[6] Nuffield Centre for International Health and Development of the Uol has been providing postgraduate training programs to the world's health professionals since the 1970s. It is recognized as a WHO Collaborating Centre on Research and Capacity Strengthening of Health Policy, Governance and Services, and is one of UK's most established and successful centers for health systems research, education, and teaching. The center has a well-established and popular portfolio of postgraduate and undergraduate courses. Alongside teaching, research carried out by the academic staff of the center and its international partners generates new knowledge to improve the health of communities in low and middle income countries. The center has extensive international networks to facilitate dissemination of project outputs; and contributes to the design and quality assurance of the Public Health Program, Continuous Professional Development, and subsequent cogeneration of new courses and content in the beneficiary university UG/PG curricula, partner mentoring, and dissemination and uptake of work via external networks and stakeholders.

\section{Approach to Partnership}

Formulation of the program was initiated initially through online communication between the two institutions. Primary concerns include the agreed curriculum, teaching staff, capacity building of the teachers, teaching materials, assessment scheme of teachers and students, matriculation fees, and sustainability of the program. On-site visits in both universities were performed with discussion on the following topics:

- Business case - program objectives, timescale for approval, admission requirement, immigration and visa requirement, recruitment target and break even points, university cost, student cost, marketing, due diligence return, risk assessment, and legal agreement.

- Academic content and management of the program - assessment, program management, program structure, teaching staff, student and staff support, and quality assurance.

\section{Strategic Planning and Market Study}

The UST MPHI staff engaged into a strategic planning session. The following was formulated:

- Mission - To be recognized as a center of excellence in international public health through education, research, and community service.

- Vision - By 2023, the UST-FMS and UoL have established a sustainable MPH international program.

Moreover, the faculty staff established several workshops for capacity building and connection to peers. Two symposia were held and prominent public health experts from the WHO, Department of Health, Philippine Red Cross, and other public and private agencies participated.

An extensive marketing study was performed to obtain an in-depth understanding of the program needs and to know what could make the program more acceptable to the potential target. The program targets those who would like to engage in international public health at any level of their professional career; a new graduate from a healthrelated degree or a professional shift. Highlights of the marketing studies for the MPHI program showed the following:

- The UST and UoL MPHI partnership is a unique and strong program.

- Financial and emotional barriers of studying abroad must be addressed.

- The program has broad appeal to professionals from various fields.

\section{Master of Public Health International (MPHI) Program Proper}

The primary objective of the MPHI program is to establish knowledge and skills in the theory and practice of public health with emphasis on 


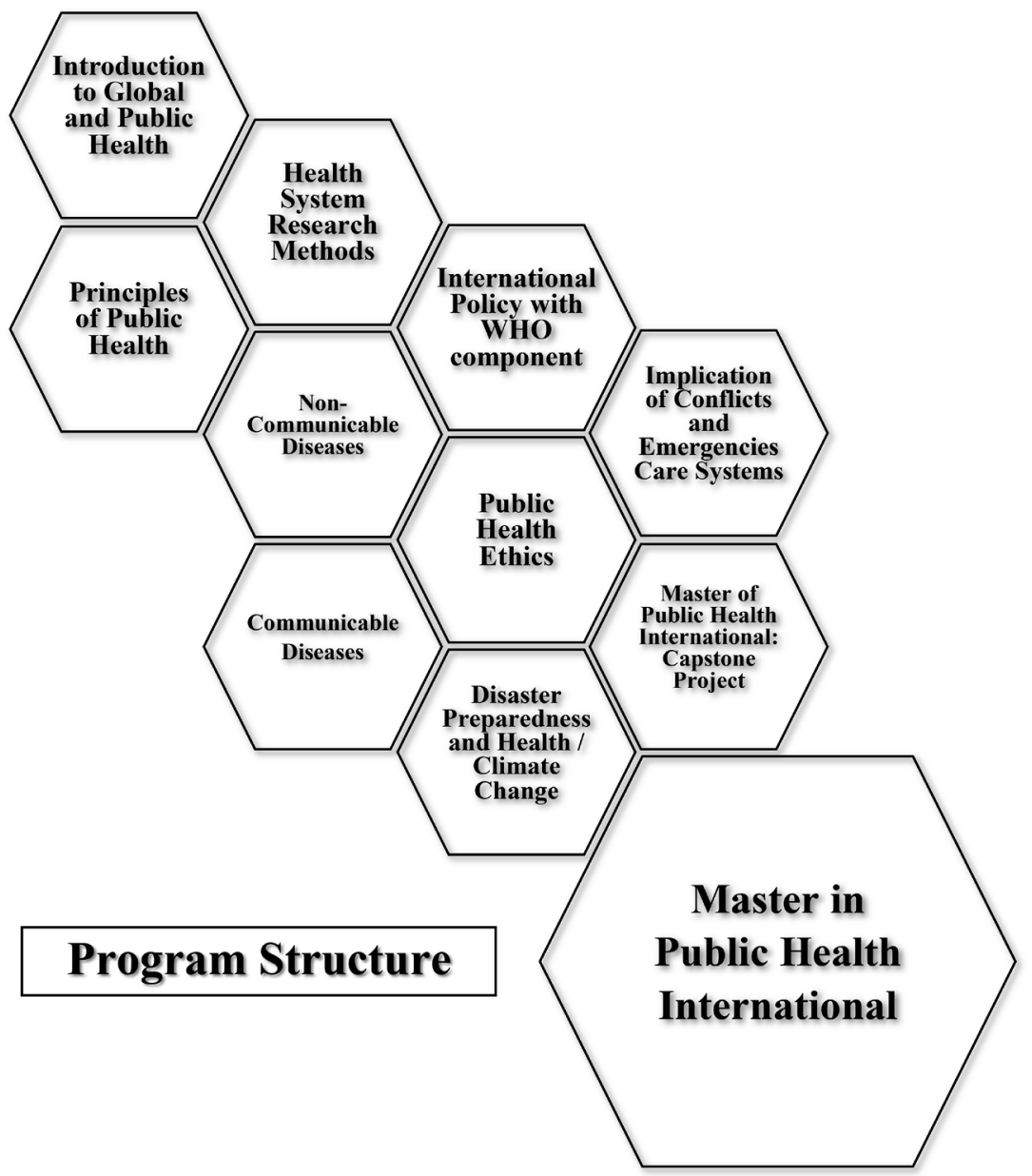

Figure 2. Scheme of the Master in Public Health International program of the University of Santo Tomas, Faculty of Medicine and Surgery and Nuffield Centre for International Health and Development of the University of Leeds.

international issues, settings, and practice, and with focus on the middle- and low-income Asian regions. This is a laddered program with a single award to be given by the UST with a Postgraduate Certificate from the Uol.

\section{Program Structure}

The program runs for 18 months. The students spend four months at the UoL in UK for completion of two modules: Introduction to Global and Public Health and Principles of Public Health (Term 1). Term 2 and Term 3 will be in the UST on weekend and summer classes. The subjects are: Health System Research Methods, Non-Communicable Diseases, Communicable Diseases, Disaster Preparedness and Health/Climate Change, Implication of Conflicts and Emergencies Care Systems, International Health Policy with the WHO component and Public Health Ethics. The last term (Term 4) is for the 6-month capstone on national or international projects with publication of work (Figure 2).

\section{Description of Specific Modules}

The two modules from the NCIHD of the UoL are as follows:

- Introduction to Global and Public Health - The aim of this module is to introduce students to the study of global and public health providing the foundation for subsequent learning on their programs. This learning includes understanding the principles, concepts, and frameworks of health; measuring and interpreting key health issues; knowing how responses to global health issues are planned and implemented; and understanding the global health policy context for such responses.

- Principles of Public Health - This module provides students with an opportunity to acquire essential 
public health competence in order to work in an international context. The module will focus on selected public health issues, their analysis and selection of appropriate strategies.

On the other hand, the modules from the UST-FMS are as follows:

- Health System Research Methods - This is an outcome-based study of the basic concepts and processes of health systems research methodology in the national and international context of public health. It focuses on the application of theoretical and practical aspects of health systems research using epidemiology, statistics, and evidence-based public health interventions. At the end of the course, the students are expected to develop a research proposal demonstrating their understanding of basic health research methodology.

- Non-Communicable Diseases (NCDs) - This is a course which provides an integrated approach to NCDs. There will be a discussion on the four main types of NCDs such as, cardiovascular diseases, cancers, chronic respiratory diseases, and diabetes. The course focuses on risk factors for NCDs, socioeconomic impact of NCDs, and prevention and control of NCDs.

- Communicable Diseases - A constructivist aligned outcomes-based course on the comprehensive study and application of principles of communicable diseases from pathophysiology to their management and prevention in the context of current practices, recent researches, and contemporary critical issues. The focus is on fundamentals of microbial infection including antibiotic resistance, common communicable and tropical diseases, sexually transmitted infections including HIV/ AIDS, emerging and re-emerging infections, and infection control and prevention.

- International Health Policy with the WHO component - This course introduces the student to applied health policy and economic disciplines to meet the growing demands for healthcare professionals in evaluating and measuring health outcomes (both physical and humanistic) and to ascertain economic consequences of healthcare interventions by determining the optimal clinical effectiveness, comparative effectiveness, and economic value.

- Disaster Preparedness and Health/Climate Change - 1) Disaster Preparedness - This course introduces students to the different aspects of natu- ral and man-made disasters while integrating public health research designs and practices. Class lectures and discussions use recent and historical case studies as a basis for developing critical thinking and leadership skills needed by healthcare professionals in crisis situations, international, domestic, and regional settings are addressed, as well as the social, economic, and political aspects of disaster planning, preparedness, and mitigation, and 2) Health/Climate Change - This course provides an in-depth analysis on the burden of disease of climate change and is specially designed to help equip health professionals with the knowledge and skills necessary to deal with the adverse effects of climate change on human health. Factors that make individuals and populations vulnerable to the effects of climate change will be tackled, as well as policies (both local and international) that address the risks of climate change.

- Implication of Conflicts and Emergencies Care Systems - This module examines the meaning, types, magnitude, and implications of emergencies on health and health care systems in low-middle income countries and ways to deal with them. Students are introduced to the issue of refugees and displaced people, which are often a consequence of conflict and emergency situations, as well as policy options for the rehabilitation of health systems.

- International Health Policy with WHO Component - Students will be exposed to policy-making and program formulation through exposures to various international agencies including the $\mathrm{WHO}$. Public health experts from these organizations will be invited as guest lecturers to impart their experience and knowledge.

- Public Health Ethics - This course is intended to analyze and discuss relevant ethical challenges surrounding international public health from national, regional to international strata. The course will be more focused on the communitarian concerns rather than a single doctor-patient relationship revolving around recent public health concerns with global significance. General issues include health research, global threats of communicable and NCDs and human rights.

\section{Geneva Study Tour}

The study tour is an optional module from the UoL. This module exposes post-graduate students to the 
international health policy environment. They will have the opportunity to visit the WHO headquarters in Geneva and other major international organizations (including the United Nations, World Council of Churches, International Hospital Federation, World Vision, Médecins Sans Frontières, International Labour Organization, Office of the UN High Commissioner for Human Rights and International Committee of the Red Cross) over five days. Visits will comprise of a combination of lectures, seminars, demonstrations, tours, small group discussion, and individual discussions/interviews. The module will be assessed by a presentation and submission of findings from an assessment of an international health issue/policy. The outline of this project will be discussed and approved by the module leaders before the visit. Two members of staff from the NCIHD (not necessarily the module leaders) will accompany the students on the field trip.

\section{The Capstone}

The primary objective of the capstone project is to apply the learnings in UoL and the UST on policymaking and recognition of public health needs in the community. Proposals for the capstone project will require approval of the UST MPHI staff with specific assigned advisers.

The first cohort of students collaborated their projects with the UST-Simbahayan Community Development, an office tasked to develop, implement, and manage the University Community Development Program (UCDP). After identifying the partner community, formal arrangement with the local officials was instituted. The students stayed and immersed with the community.

The primary objective of this specific capstone project is to identify the public health needs of the community. The students formulated programs on the recognized needs based on individual student's professional background, as follows:
- Community-Based Mental Health Program

- Prevention of Cardiovascular Diseases Through Risk Factor Reduction

- Community-Based Tobacco Intervention Project in an Urban Settlement

- Assessing the Effectiveness of a Capacity Building Intervention in Empowering the Urban Poor Community

- A Pilot Edible Gardening Program for Food Security in a Low-Income Filipino Community

- Community-Based Deworming Program

Briefly, the targeted groups such as housewives, parents, disaster preparedness team, and health workers were convened with the assistance of community leaders. Educational materials were formulated and delivered through scheduled fora. All participants were assessed with specific posttest tools. Copies of the completed papers were distributed to the respective local officials. The respective project manuscript was submitted for publication to complete the requirements of the program.

\section{SUMMARY AND CONCLUSION}

In conclusion, the foregoing discussion aptly describes how two international institutions collaborated to establish an international program in public health. The common vision of these two international institutions, the UST-FMS and UoL $\mathrm{NCIHD}$ was to establish and strengthen knowledge and skills in the theory and practice of international public health with focus on the middle- and lowincome Asian regions that brought forth a TNE model that is beneficial to both. The exchange program was made possible through the support from each countries' respective agencies, the CHED and the British Council. 


\section{REFERENCES}

1. Walden University. What is public health and why is it important? [Internet]. Walden University. [cited 2021 Dec 26]. Available from: https:// www.waldenu.edu/programs/health/resource/ what-is-public-health-and-why-is-it-important

2. Bjørn Jensen L, Lukic I, Gulis G. The delivery of health promotion and environmental health services; Public health or primary care settings? Healthcare (Basel) [Internet]. 2018;6(2). Available from: http://dx.doi.org/10.3390/ healthcare6020042

3. Mastersportal.com. [cited 2021 Dec 26]. Available from: https://www.mastersportal.com/articles/2730/pros-andcons-of-mph-degree-jobs-in-2022.html

4. MacArthur S. Top $25 \mathrm{MPH}$ in global health programs [Internet]. MPH Online. 2018 [cited 2021 Dec 26]. Available from: https://www.mphonline.org/best-global-health-mph/

5. QS Top Universities. Retrieved from: https://www.topuniversities.com/universities/university-santo-tomas

6. What is the TEF? Results of the teaching excellence framework 2019 [Internet]. Times Higher Education (THE) - Student. 2019 [cited 2021 Dec 26]. Available from: https://www.timeshighereducation.com/student/blogs/ what-tef-results-teaching-excellence-framework-2019 (c) (i) (2) Open Access This article is licensed under a (c) NG SA Creative Commons Attribution-NonCommercialShareAlike 4.0 International License, which permits use, share - copy and redistribute the material in any medium or format, adapt - remix, transform, and build upon the material, as long as you give appropriate credit, provide a link to the license, and indicate if changes were made. You may do so in any reasonable manner, but not in any way that suggests the licensor endorses you or your use. You may not use the material for commercial purposes. If you remix, transform, or build upon the material, you must distribute your contributions under the same license as the original. You may not apply legal terms or technological measures that legally restrict others from doing anything the license permits. The images or other third party material in this article are included in the article's Creative Commons license, unless indicated otherwise in a credit line to the material. If material is not included in the article's Creative Commons license and your intended use is not permitted by statutory regulation or exceeds the permitted use, you will need to obtain permission directly from the copyright holder. To view a copy of this license, visit https://creativecommons.org/licenses/by-nc-sa/4.0/. 